\title{
PELATIHAN PENATALAKSANAAN FARMAKOLOGIS HIPERTENSI MENINGKATKAN KETERATURAN MENGKONSUMSI OBAT PADA PENDERITA HIPERTENSI
}

\author{
*Yustina Kristianingsih, **Anastasia Made Seruni \\ STIKES Katolik St. Vincentius a Paulo Surabaya \\ e-mail: tina_fw@yahoo.com
}

\begin{abstract}
Abstrak
Penyakit hipertensi merupakan peningkatan tekanan darah yang memberi gejala yang berlanjut untuk suatu target organ, seperti stroke dan penyakit jantung koroner. Hipertensi yang seringkali tidak menimbulkan gejala merupakan penyebab terbesar dari ketidakpatuhan melaksanakan pengobatan. Ketidakpatuhan terhadap program terapi merupakan masalah yang besar pada penderita hipertensi. Sehingga penderita hipertensi perlu mendapatkan pelatihan tentang penatalaksanaan farmakologis hipertensi. Desain penelitian pra eksperimental dengan one group pre dan post test desingn. Responden yang menjadi subjek dalam penelitian ini adalah 51 penderita Hipertensi yang telah di diagnose dokter yang tidak teratur dalam mengkonsumsi obat anti hipertensi. Alat pengumpulan data berupa kuesioner Morisky Medication Adherance Scala (MMAS) untuk mengukur keteraturan menhkonsumsi obat sebelum dan sesudah pelatihan. Hasil uji menggunakan Wilcoxon didapatkan hasil $p=0.000<\alpha$ 0,05 , yang berarti terdapat pengaruh antara pelatihan penatalaksanaan farmakologis terhadap keteraturan mengkonsumsi obat anti hipertensi di posyandu Mawar RW IV Kelurahan Pakis Kecamatan Sawahan Surabaya. Sehingga di harapkan Kader posyandu Lansia bekerjasama dengan puskesmas Sawahan untuk memberikan pelatihan tentang penatalaksaan hipertensi kepada keluarga yang memiliki anggota keluarga yang menderita hipertensi agar dapat memberikan dukungan sehingga dapat meningkatkan keteraturan mengkonsumsi obat sehingga mencegah terjadinya komplikasi.
\end{abstract}

Kata kunci: Pelatihan, Penatalaksanaan Farmakologis, MMAS, Hipertensi

\begin{abstract}
Hypertension is an increase in blood pressure which gives the symptoms continue for a targeted organ, such as stroke and coronary heart disease. Hypertension often does not cause symptoms are the biggest cause of non-compliance carry out the treatment. Poor adherence to treatment programs is a major problem in patients with hypertension. So that people with hypertension need to be trained in the pharmacological management of hypertension. Preexperimental research design with one group pre and post test desingn. Respondents who become subjects in this study were 51 patients with hypertension who have been in the diagnosis doctors irregular in taking anti-hypertensive medications. Data collection tool was a questionnaire Morisky Medication Adherance Scala (MMAS) to measure the regularity used drugs before and after training. The result of using the Wilcoxon test showed $p=0.000<\alpha$ 0.05 , which means that there is influence between pharmacologic management training to order taking antihypertensive drugs in posyandu Mawar RW IV Village Ferns Sawahan Surabaya. So the expected Heath Volunter Elderly collaboration with health centers to provide training Sawahan hypertension containment procedures to families who have family members who suffer from hypertension in order to provide support in order to improve the regularity of taking the drug so as to prevent the occurrence of complications.
\end{abstract}

Keywords: Training, Pharmacological Management, MMAS, Hypertension 


\section{Pendahuluan}

Hipertensi dapat didefinisikan sebagai peningkatan tekanan darah yang menetap diatas batas normal yaitu tekanan sistoliknya $\geq 140$ $\mathrm{mmHg}$ dan tekanan diastolistik $\geq 90$ mmHg.Hipertensi yang seringkali tidak menimbulkan gejala merupakan penyebab terbesar dari ketidakpatuhan melaksanakan pengobatan. Ketidakpatuhan terhadap program terapi merupakan masalah yang besar pada penderita hipertensi. Diperkirakan 50\% diantara penderita hipertensi menghentikan pengobotan dalam 1 tahun setelah tekanan darahnya terkontrol sehingga seringkali menimbulkan komplikasi (Smeltzer and Brenda Bare, 2002) .

\section{Keberhasilan pengobatan hipertensi perlu ditingkatkan dengan melaksanakan promosi kesehatan dengan melibatkan tenaga kesehatan dan sistem pendukungnya dari penderita hipertensi. Perawat sebagai bagian dari tenaga kesehatan merupakan faktor yang mempunyai peran penting dalam merubah perilaku pasien sehingga terjadi kondisi keseimbangan dan kemandirian. Salah satu model yang dapat digunakan oleh seorang perawat untuk merubah perilaku penderita adalah dengan memberikan pelatihan.}

Pemberian dukungan pelatihan ini salah satunya adalah dengan memberikan pendidikan kesehatan secara bertahap dan berkelanjutan dengan memperhatikan masalah-masalah yang dialami oleh pasien sehingga tercapai kesadaran akan penyakitnya dan hasil akhirnya adalah perbaikan perilaku penderita (Maurer, 2009).

\section{Metode}

Metode penelitian yang digunakan Praexperimental dengan pendekatan onegrouppreposttestdesign. Variabel independent adalah pelatihan penatalaksanaan farmakologis dan variabel dependennya adalah keteraturan mengkonsumsi obat anti hipertensi. Populasi yang digunakan adalah penderita hipertensi di RW IV Kelurahan Pakis Kecamatan Sawahan Surabaya yang memenuhi kriteria inklusi diantaranyasudah terdiagnosa oleh dokter, dan tidak teratur dalam mengkonsumsi obat, bisa membaca dan menulis. Besar sampel dalam penelitian ini sejumlah 51 responden.

Penelitian dilakukan di posyandu Lansia Mawar RW IV Kelurahan Pakis Kecamatan Sawahan Surabaya mulai tanggal 7-23 Agustus 2014. Proses pengambilan data dilakukan dengan melakukan pengukuran keteraturan mengkonsumsi obat anti hipertensi menggunakan Morisky Medication Adherance Scale (MMAS).

Penderita hipertensi yang sudah didiagnosa dokter, tidak teratur dalam mengkonsumsi obat, dan bisa membaca serta menulis, kemudian diukur keteraturan mengkonsumsi obat anti hipertensi kuesioner MMAS kemudian diberikan intervensi berupa pelatihan selama 2 kali selama 12 hari, dan diakhiri dengan pengukuran keteraturan mengkonsumsi obat anti hipertensi pasca intervensi. Data dianalisis dengan membandingkan keteraturan mengkonsumsi obat sebelum dan sesudah pelatihan. Uji statistic dilakukan dengan menggunakan Wilcoxon untuk mengetahui perbedaan keteraturan mengkonsumsi obat sebelum dan sesudah pelatihan dengan taraf signifikan, $\alpha=0,05$. 


\section{Hasil}

Tabel 1. Karakteristik Responden

\begin{tabular}{llll}
\hline NO & KRITERIA & N & $\%$ \\
\hline 1 & Usia & & \\
& $50-60$ & 5 & 10 \\
& $61-70$ & 30 & 59 \\
& $71-80$ & 14 & 27 \\
& $>80$ & 2 & 4 \\
2 & Jenis kelamin & & \\
& Perempuan & 39 & 76 \\
& Laki-laki & 12 & 24 \\
& Tingkat Pendidikan & & \\
& SD & 28 & 55 \\
& SMP & 14 & 27 \\
& SMA & 7 & 14 \\
& PT & 2 & 4 \\
& Lama menderita HT & & \\
& <1 tahun & 8 & 16 \\
& 1-2 tahun & 3 & 6 \\
& 3-4 tahun & 17 & 33 \\
& >5 tahun & 23 & 45 \\
5 & Olah Raga & & \\
& Olah Raga Rutin & 40 & 78 \\
& Tidak Rutin Olah Raga & 11 & 22 \\
6 & Status & & \\
& Menikah & 27 & 53 \\
& Janda/duda & 24 & 47 \\
& & & \\
\hline & & &
\end{tabular}

Tabel 1 menunjukkan sebagian besar responden berjenis kelamin perempuan, berusia $61-70$ tahun, berpendidikan SD, mengkonsumsi obat dan lama menderita Hipertensi $>5$ tahun, rutin berolah raga dan berstatus menikah.

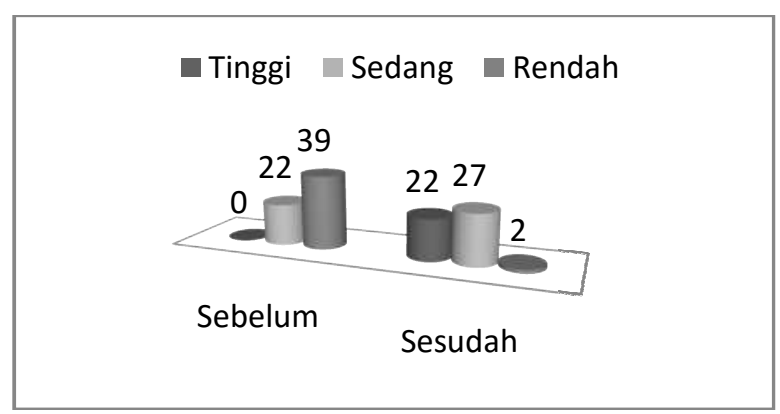

Diagram 1 Perbedaan keteraturan mengkonsumsi obat anti hipertensi sebelum dan sesudah pelatihan panatalaksanaan farmakologis

Hasil uji satatistik didapatkan nilai $\mathrm{p}=$ 0,000 oleh karena $\mathrm{p}<\alpha$, maka terdapat peningkatan keteraturan mengkonsumsi obat anti hipertensi pada penderita hipertensi.

\section{Pembahasan}

Hasil penelitian didapatkan dataketeraturan mengkonsumsi obat anti hipertensi setelah diberikan pelatihan penatalaksanaan farmakologis dari 51 responden 27 responden memiliki keteraturan sedang, 22 responden memiliki keteraturan tinggi dan 2 responden memiliki keteraturan rendah. Semua responden menunjukkan perbaikan nilai meskipun masih ada yang berada pada tingkat keteraturan rendah. Pelatihan merupakan kegiatan yang dilakukan secara sengaja untuk mencapai tujuan tertentu. Terdapat dua jenis pelatihan yaitu pelatihan soft skill dan hard skill. Pelatihan hard skill merupakan suatu pelatihan mengenai pengenalan atau pendalaman ketrampilan yang individu,kelompok, organisasi atau lembaga baik secara teknis (Hard Skill) maupun bersifat non teknis yang lebihn bersifat pada pengembangan pribadi (Soft Skill) (Gulo, 2002). Pelatihan mengenai penatalaksanaan farmakologis pada penelitian ini diberikan dengan menggunakan metode caramah, pemberian kartu obat, demonstrasi dan pendampingan pengisian kartu obat. Hal ini sesuai dengan teori bahwa pemberian pelatihan dapat memperbaiki perilaku seseorang khusnya penguasaan ketrampilan dalam mengkonsumsi obat.

Adanya responden yang masih memiliki keteraturan sedang dan juga rendah menurut pendapat peneliti ini dipengaruhi oleh beberapa factor seperti usia responden yang semuanya sudah lansia sehingga terdapat penurunan fungsi fisiologis dan psikologis yang mempengaruhi dalam proses penerimaan informasi sehingga menghampat perubahan perilaku khususnya keteraturan mengkonsumsi obat.

Berdasarkan hasil penelitian dapat diketahui peningkatan keteraturan megkonsumsi obat anti hipertensi sebalum dan sesudah pelatihan penantaksanaan farmakologis dimana jumlah responden yang memiliki keteraturan tinggi menjadi 22 responden, yang memiliki 
keteraturan sedang dari 22 menjadi 27 responden dan yang memiliki keteraturan rendah dari 39 menjadi 2 responden.

Hasil uji satatistik menggunakan uji Wilcoxon dengan menggunakan $\mathrm{SpSS}$ for windows didapatkan nilai $p=0,000<\alpha \quad 0,005$ yang berarti H0 ditolak, terdapat pengaruh pelatihan penatalaksaan farmakologis pada penderita hipertensi terhadap keteraturan mengkonsumsi obat anti hipertensi.

Pelatihan merupakan suatu proses pembelajaran yang lebih menekankan pada praktik sasaran yang dilakukan seseorang atau kelompok dengan menggunakan pendekatan pembelajaran dan bertujuan meningkatkan kemampuan ketrampilan dalam satu atau beberapa ketrampilan tertentu (Santoso, 2011). Dimana pada penelitian iniresponden diberikan pelatihan tentang penatalaksanaan farmakologis pada penderita hipertensi dengan tujuan untuk meningkatkan keteraturan mengkonsumsi obat anti hipertensi.

Hasil penelitian menunjukkan kesesuaian dengan teori dimana pelatihan yang diberikan memberikan pengaruh pada keteraturan mengkonsumsi obat penderita diabetes. Hal ini dapat dibuktikan dengan menurunnya jumlah responden yang memiliki keteraturan rendah dan meningkatnya responden yang memilikin keteraturan sedang dan tinggi. Selain itu dengan pelatihan yang menggunakan metode pendampingan pengisian kartu obat dan pemantauan yang rutin dilakukan dapat meningkatkan keteraturan dalam mengkonsumsi obat. Sehingga pendampingan daan dukungan dalam mengkonsumsi obat ini pentig untuk selalu diberikan baik oleh keluarga dan atau orang terdekat, sesame penderita hipertensi dan petugas kesehatan.

\section{Simpulan dan Saran}

Ada pengaruh pelatihan penatalaksanaan farmakologis terhadap keteraturan mengkonsumsi obat anti hipertensi di Posyandu Mawar Kelurahan Pakis Kecamatan Sawahan. Pelatihan yang dilakukan dengan mengunakan metode demontrasi dan juga mengenai hard skill akan meningkatkan perubahan perilaku keteraturan dalam mengkonsumsi obat anti hipertensi.

Sesuai dengan hasil penelitian bahwa pelatihan dapat meningkatkan keteraturan mengkonsumsi obat maka diharapkan kepada Kader posyandu lansia mawar dapat bekerja sama dengan puskesmas untuk memberikan pelatihan penatalaksanaan hipertensi bagi keluarga pasien yang menderita hipertensi agar keluarga memiliki pengetahuan yang baik sehingga dapat memberikan dukungan kepada anggota keluarganya yang menderita hipertensi dalam menjalani pengobatan dan menghindari terjadinya komplikasi hipertensi lebih lanjut.

\section{Daftar Pustaka}

Arikunto, Suharsini. (2006). Prosedur Penelitian Suatu Pendekatan Praktik. Jakarta: Rineka Cipta.

Bart, Smet. 1994. Psikologi Kesehatan. Jakarta: Grasindo

Corwin. Elizabeth J. 2009. Buku Saku Patofisiologi. Jakarta :EGC.

Depkes RI. (2008). Laporan Riset Kesehatan Dasar 2007 Provinsi Jawa Timur. Jakarta: Badan Penelitian dan Pengembangan Kesehatan Departemen Kesehatan RI

Diwanto, Masde Al. (2009). Tips Mencegah Stroke, Hipertensi dan Serangan Jantung. Yogyakarta: Paradigma

Gunawan, Lany. (2001). Hipertensi: Tekanan Darah Tinggi. Yogyakarta: Kanisius

Hartono, LA. (2007). Stres dan Stroke. Yogyakarta: Kanisius

Hidayat, A. Aziz Alimul. (2003). Riset Keperawatan Dan Teknik Penulisan Ilmiah. Jakarta: Salemba Medik .(2007).

Keperawatan Dan Teknik Penulisan

Riset Ilmiah Edisi 2. Jakarta: Salemba Medika

Maurer, A.F, Smith.M.S., 2005. Community/Public Health Nursing Practice: Health for Family and Population. Philadelphia : W.B. Saunders

Morisky D. E, Ang A, Marie K., Harry J W. 2008. Predictive Validity of a Medication Adherence Measure in an 
Outpatient Setting. the Journal of Clinical Hypertension

Nazir, Moh. (2003). Metode Penelitian. Jakarta: Ghalia Indonesia

Niven, 2000. Psikologi Kesehatan: Pengantar untuk Perawat dan Profesional Kesehatan Lain. Jakarta : EGC

Nursalam. (2003). Konsep dan Penerapan Metodelogi Penelitian Ilmu Keperawatan, Pedoman Skripsi, Tesis, dan Instrument Penelitian Keperaawatan Ed. 2. Jakarta: Salemba Medika

Patrick Davey. 2005. At a Glance Medicine. Jakarta : Erlangga

Purwanto, Heri. (1994). Pengantar Statistik Keperawatan. Jakarta:EGC

Puspitorini, Myra. 2008. Hipertensi: Cara Mudah Mengatasi Tekanan Darah Tinggi. Jogjakarta: Image Press

Ridwan, Muhamad. (2009). Mengenal, Mencegah, Mengatasi Silent Killer: Hipertensi. Jawa Tengah: Pustaka Widyamara

Santoso, Budi. 2011. Skema dan Mekanisme Pelatihan Penduan Penyelanggaraan Pelatihan. Jakarta: Terangi

Setiadi. (2007). Konsep Dan Penulisan Riset Keperawatan Edisi 1. Jakarta: Graha Ilmu

Smeltzer, Suzanne C. (1996). Buku Ajar Keperawatan Medikal-Bedah Brunner \& Sudart. Edisi 8 vol:1. Alih bahasa: Agung Waluyo, et all. (2001). Jakarta: EGC

Tambayong. Jan. 2009. Patofisiologi untuk Keperawatan. Jakarta: ECG.

Tim Penyusun Pusat Pembinaan dan Pengembangan Bahasa. 1990. Kamus Besar Bahasa Indonesia. Cet. 3. Jakarta: Balai Pustaka

W. Gulo. 2002. Strategi Belajar Mengajar. Jakarta: Grasindo 